\title{
Puzzled by realism: a response to Deichsel
}

\author{
USKALI MÄKI \\ University of Helsinki
}

Keywords: realism, anti-realism, truth, models, economic methodology JEL Classification: B40, B41, B49

No realist project in and about economics is close to completion. There are many open issues that remain to be addressed and resolved. Simon Deichsel (2011) has written a healthy challenge that should offer some useful inspiration to anyone interested in assessing and perhaps contributing to the realist projects. He argues against realism and in support of some sort of anti-realism. My response first deals with some conceptual issues regarding the very ideas of realism and anti-realism. I will then discuss the role of pragmatics in relation to truth. Finally, I will address the issue of justifying realism-Deichsel's title, after all, suggests his challenge is directed against what he calls the pragmatic justification of realism. My remarks are both brief and selective.

\section{REALISM, ANTI-REALISM, AND SUSPENDING JUDGEMENT ABOUT TRUTH}

Deichsel defends what he calls anti-realism against realism. It is important to see how he defines "anti-realism" and that he does it disjunctively (Deichsel 2011, 24). Accordingly, anti-realism is the thesis that we should:

[1] "suspend judgement on the truth and truth-worthiness of our theories" or

[2] "avoid talking about the truth of theories altogether" and we should do so

[3] "in order to minimize the confusions that surround this concept" (that of truth). 
Each of these elements requires attention. Element [1] is particularly interesting when presented as a defining feature of anti-realism. It so happens that it is precisely this idea that I have emphasized elsewhere as (a) compatible with realism, and (b) important for realist accounts of some disciplines at some stages of their development (e.g., Mäki 2005).

Let me explain. (a) First, [1] is compatible with what I have called minimal realism for which it is enough if a theory has a chance of being true, and that it is true or false in virtue of how the world works. I take anti-realism to deny this and to claim that theories have no chance of being true in this sense: either no talk about truth makes sense or truth should be conceived in terms other than how theories relate to the world (such as usefulness, coherence, or consensus). (b) Second, there are many situations (fields of inquiry, disciplines, stages of their development, and so forth) in which one should not rush to pass judgement about the truthfulness of a theory; one should rather suspend judgement, sometimes for long periods of time. One is not entitled to pass judgement because of the high degrees of epistemic uncertainty characteristic of these situations. The reasons for uncertainty can be many, such as the subject matter being very complex or otherwise hard to access; the discipline being at its formative or explorative stages of development; research being heavily shaped by commercial or ideological interests; and so on.

Whatever the reason for uncertainty, in order to be able to suspend judgement on the truth of a theory in the first place, one must presuppose a minimal realism about theories having a chance of being true or false. This is independent of whether we are in an actual position to pass judgement. In short, I do not consider [1] an anti-realist principle at all. It is rather a realist principle well suited for research fields in situations characterized by severe epistemic uncertainty. Even radical scepticism-suspending judgement indefinitely-would be compatible with realism.

There are of course many notions of realism available, and while Deichsel acknowledges this, it often seems he wants a realist to subscribe to something stronger than just minimal realism. He would like the realists to tell how epistemic access to the real world is ensured-what precise criteria, procedures, and standards to apply so as to be able to pass judgement. So it seems he would like me to subscribe to the possibility of what he calls "strong epistemic realism". 
But this is exactly what I have explicitly refused to advocate as the only sensible and defensible version of realism.

When an anti-realist suspends judgement in the vein of Deichsel, [1] seems to suggest that the judgement is about truth rather than something else. And as I said, this presupposes minimal realism about truth. But then saying that realism "allows talking about truth where anti-realism suspends judgement on this matter" (Deichsel 2011, 34) is a little confusing given that one can obviously talk about truth without passing judgement. One does not need a lot of "talking about truth" in order for those suspended judgements to be about truth.

What about [2] and [3]? Deichsel suggests that anti-realists avoid talking about truth in order to avoid confusions around the concept of truth. I am not attracted by this disjunct either. There are many confusing concepts around. Think of value, utility, preference, rationality, wellbeing, coordination, equilibrium, market, institutions (and economics!); or think of causation, explanation, theory, model, justified belief (or empirical adequacy and problem-solving capacity, Deichsel's favourites). Should we (economists, philosophers of economics, or others) avoid talking about those things just because there is confusion around the concepts? Should we surrender rather than meet the challenge of bringing light to darkness? Should we take the easy way and avoid the hard task of trying to remove or minimize confusion? No, we should not-regardless of whether we are realists or anti-realists. Scientists talk about truth and falsehood and no doubt often do it in a confused and confusing manner. But I take it as the task of philosophy to remove or reduce conceptual confusion. With respect to truth talk, philosophy is nowadays in a much better position than some decades ago to do this thanks to the recent resurgence of philosophical interest in theories of truth (see, e.g., Alston 1996; Vision 2004).

\section{TRUTH AND PRAGMATIC MATTERS}

As I see it, truth is not pragmatic, while pragmatics plays very important roles in the search for truths. Whatever we take the relevant truth bearers to be-such as thoughts, beliefs, sentences, propositions-they are true or false not in virtue of whether they are useful, convenient, justified, rationally acceptable, warrantedly assertable, persuasive, credible, collectively agreeable, or generally in virtue of having any such pragmatic property. Very roughly, truth bearers are true or false in 
virtue of the way the world is. An assumption of increasing returns in an industry is true if the returns are increasing in that industry. A model of a real-world mechanism representing it as a positive feedback mechanism is true if the mechanism is a positive feedback mechanism. The assumption and the model are not true or false based on whether they are useful or convenient or persuasive, whether evidence is taken to support them or the research community generally accepts them as solving research problems.

Even though I do not take truth to be pragmatic, it makes no sense to talk about truth in scientific inquiry without simultaneously talking about pragmatic matters. The relevant notion of truth is that of relevant truth. And relevance is pragmatic: whatever is relevant is so relative to goals, purposes, practices, questions, problems. This means relevant truths are relative to, or constrained by, purposes and problems, questions and quandaries. No truth is a relevant truth if it fails to serve a set purpose or to answer a posed question.

The notion of relevant truth has two important consequences. One is that it helps see why and how all theories and models necessarily represent only very limited and selective aspects of some subject matter, and can do so truthfully. The correct selection or isolation is a function of the questions and purposes served. One isolation serves one purpose, while another serves another purpose. Some questions can be answered in terms of very simple models, while other questions may require very complex models.

It is a mistake to think that a richer model is always more truthful per se. A related mistake is the common belief that a model can be taken closer to the truth by de-isolation, by relaxing its unrealistic assumptions and replacing them with more realistic assumptions, and in this way incorporating previously missing details. As I have frequently argued elsewhere (e.g., Mäki 2011a), a realist should be fully comfortable with simple models and unrealistic assumptions provided they serve good purposes such as the acquisition of relevant truths about simple facts of the matter. Therefore, it is not at all an anti-realist privilege to maintain that "more realistic assumptions are not always better ones" (Deichsel 2011, 39).

I also do not see why Deichsel thinks it is a "realist fallacy" (that he attributes to Lawson) to assume that "higher realisticness [...] should be an end in itself" (p. 38). Realists should not commit such a fallacy. Many relevant truths can be attained-and often can only be attained-with 
lower degrees of realisticness. Naturally, this must be understood with a qualification that acknowledges the ambiguity of '(un)realisticness': unrealistic (sensu A) models can be realistic (sensu B).

The second important consequence of focusing on relevant truth rather than on truth per se is based on the recognition that relevance is a function of purposes and questions and that there are $a$ variety of possible purposes and questions that themselves can and should be critically assessed. In order to be relevantly true, a truth bearer must be true and must serve a given purpose; relevance provides a link between truth and purposes. This means that a claim to relevant truth can be critically examined by separately raising questions about truth, about purposes, and about relevance. So if you want to challenge an economic model, or rather a family of models, you can ask (i) whether the models are true of their target; (ii) whether the models serve given purposes; and (iii) whether important purposes are being served. This simple classification gives us three forms of failure and helps us to be more focused in criticizing exercises of modelling. For example, within this framework, one can proceed to diagnose the alleged failure of macroeconomic models with respect to the present economic crisis, tracing the failure to its sources.

Deichsel seems to think of science in terms of problem-solving and that this might somehow speak in favour of anti-realism. So let me put forth a few remarks on this. Problems are in the family of pragmatic matters that provide criteria of relevance. But just to talk about problems and problem-solving in general sounds too abstract. All inquiry is problem-solving of some sort, but this alone is not very informative simply because problems come in so many different varieties. At one end there are problems related to the existence of an entity or a numerical value of its property, while at the other end there are problems that, say, relate to the formal details of a mathematical technique.

Varieties of problem-solving are differently related, if at all, to the big ambition of resolving the riddles of the real world. A realist would ask questions about this relationship, granting that there are many legitimate problem-solving activities that are only very indirectly related to the big ambition and that it is often difficult to determine whether they are so related at all. It is not clear to me on what basis an antirealist would ask such questions if science were conceived merely as generic problem-solving. 


\section{JUSTIFYING REALISM?}

It is important to see that "justifying realism" remains ambiguous as long as nothing more is said about the roles and goals of realism. One does not attempt to justify realism per se, one rather justifies realism in relation to the roles it plays and the goals it might help to attain. It is one thing to consider whether realism provides a correct (descriptive) account of economics. It is quite another thing to ask whether realism can somehow be used for making economics better.

It seems that Deichsel officially focuses on the latter role of realism, which he then takes to require what he calls a "pragmatic justification" for realism. However, even though this is his official focus, he also extensively deals with the former role and the associated justifications, but fails to clearly connect the two roles with one another. This is important since this connection is the key to seeing my weak version of the "pragmatic justification" of realism.

One example of considering realism as a philosophical account of science is Deichsel's discussion of the no-miracle argument. This is part of the standard literature on scientific realism in the philosophy of science. In the standard accounts, scientific realism is presented as a strongly pro-science philosophy. It is presumed that science is a great success story, manifested in its predictive and technological achievements. Scientific realism is offered as a philosophy that explains this fact and thereby removes the apparent miracle of success. Scientific realism-defined as the claim that science has mostly gotten its theories true of the unobservable world that exists mind-independently-is presented as the best explanation for why science is successful. Because realism best explains a property of science, it is the correct description of science. This is abductive inference applied in philosophical inquiry.

I have argued elsewhere that this argument is of little relevance in the case of economics-simply because there is no obvious fact of success to be explained. Yet most of my attempts to defend realism also deal with the first (descriptive) role of realism in regard to economics, and do so without appealing to the no-miracle argument.

One of my goals - that Deichsel fails to acknowledge-has been to check whether a scientific realist account of economics is feasible. This part of my work largely relates to the debates over realism in the general philosophy of science. In these debates, some contributors have argued that scientific realism is an adequate philosophy of parts of 
science only. Indeed, it turns out that standard formulations of scientific realism are hospitable to successful physical sciences, while the social sciences threaten not to be accommodated: the latter are neither obviously successful nor do they deal with mind-independent unobservables, and the like. I have argued that scientific realism must be reformulated so as to make it more encompassing. This project not only has shown what modifications are needed in scientific realism to make it more broadly applicable, but it has also highlighted interesting and important differences between (families) of scientific disciplines. This has been part of my larger project on interdisciplinarity: scientific realism provides a philosophical framework within which disciplinary diversity can be examined (see Mäki 1996; 2005; 2011b). This is a descriptive project in regard to economics and other disciplines, but at the same time, it has consequences for how to improve our philosophical understanding of science by way of acknowledging disciplinary diversity (see Mäki 2011c). One might think that insofar as realism plays either or both of these roles with success (illuminating scientific diversity and improving the philosophical understanding of science), this will provide support to it.

This last observation relates to another ambiguity in "justifying realism": the very idea of justification can be taken to mean a number of different things. It is not fully clear to me what Deichsel takes it to mean. Given that his general suspicion seems to be that I have not given arguments for realism, one could infer that he has a very stringent view of what counts as justification. I have provided arguments that support scientific realism or at least show that scientific realism is compatible with certain important facts about economics, but this may not be strong enough for Deichsel, given his implicitly strong notion of justification. He may expect to see arguments that show why realism is necessary for accomplishing the tasks assigned to it. I am not sure my arguments have this much power, but I am convinced they do have some power-enough to justify calling them justifications.

Many of the arguments I have developed over the years have the structure of even-if arguments. I have sought to argue that even if this or that feature of economics (or its parts) is granted, there is no compelling reason to adopt a non-realist or anti-realist view of the discipline. This stands in contrast to what one might expect or what has been argued by some commentators. Even if economics uses models with false assumptions... Even if the predictions yielded by economic 
models often fail, even miserably... Even if economics deals with highly formalized mathematical structures... Even if the economy and the scientific study of it are socially constructed... Even if rhetorical persuasion plays an important role... And so on. These are arguments against the necessity of anti-realism once those features are granted; or in other words, the arguments show that those features alone are not sufficient for anti-realism. At the same time, they are arguments in support of the possibility of realism about economics. They rule out arguments against realism rather than provide direct supportive arguments for realism. Yet I find it natural to say that ruling out certain arguments against realism is a way of supporting realism. To provide support is to provide justification. But it is not to prove, or to justify beyond any further doubt or question.

These arguments do not constitute what Deichsel calls pragmatic justification. So it is somewhat incomplete to say that "Mäki's justification for taking a realist position is pragmatic insofar as he fears that giving up realism 'would result in the worst kind of complacency' [...] I call this a pragmatic justification, because it focuses on the good consequences that an adoption of realism would have" (Deichsel 2011, 24). His question is "whether Mäki can live up to the task of improving economics by means of his realism" (p. 27).

In pursuing a descriptive philosophical account of economics in interdisciplinary comparison, and in contributing to the revision of scientific realism in the philosophy of science, it is not my direct intention to help improve economics-and my proposals should be judged independently of such intentions or expectations. Yet I admit that this work is partly (but not completely) motivated by ideas about how realism might help improve economics, but these consequences are indirect.

It is also somewhat questionable to talk about "improving economics" and "good consequences" in the abstract as if these were well understood and shared ideas among people holding different philosophical outlooks - as if, that is, realist and anti-realist views of scientific progress were indistinguishable. But something like this may indeed be what Deichsel is suggesting, at least insofar as my realism and his species of anti-realism are concerned.

He asks me to show how my version of realism "would lead to an improvement of economic research and which standards it would specifically employ apart from standards that are compatible with anti- 
realism such as problem-solving capacity and empirical adequacy" (Deichsel 2011, 33). He himself does not expect realism and anti-realism to stand apart since "adopting realism does not lead to normative implications that are unavailable to the anti-realist" (p. 38). Therefore he says "realism" as I use it is "merely a brand-name" (p. 32). I suppose this implies that he takes "anti-realism" to be a brand-name as well.

I remain unconvinced. Consider the two distinctions I have proposed for distinguishing different research strategies and that Deichsel also discusses. One is between surrogate modelling and substitute modelling; the other is between merely derivational unification and ontological unification. The first couple highlights the importance of modelling in economics, while the second focuses on the highly valued goal of unification in economics. I always thought these distinctions only make sense against the background of some sort of realism and that a realist would emphasize the importance of surrogate modelling and ontological unification, while an anti-realist could be content with substitute modelling (a sort of problem-solving activity if you wish) and derivational unification (for which saving the phenomena and empirical adequacy will suffice).

One might say that even though the above two distinctions perhaps make conceptual sense, they do not make operational sense. There are no well-defined criteria or standards in terms of which we can tell apart the two kinds of modelling and the two kinds of unification. This seems to be what Deichsel thinks. For example, he believes that my distinction between ontological and merely derivational unification is useless without "a unique standard to distinguish the two modes of unification" (p. 33). Likewise, the ontological www (the way the world works) constraint on theories and models (one that I have claimed to have found in economic research practice) "is hardly a constraint at all if we cannot know when it is met" (p. 33). In the same vein, one may argue that there is no sensible distinction between realist and anti-realist conceptions of progress given that similar standards are being used.

What to make of this? My immediate reaction would be to say that I do not think operationism is any better as a principle constraining philosophical theorizing than it is in constraining scientific theorizing. In both cases, a realist insists on keeping apart the thing and our ways of measuring and knowing it. On the other hand, it is naturally a major challenge to develop ways of measuring and knowing and understanding things - these are the methods, procedures, criteria, and 
standards used in science. And just as there may be progress in theories and models of the world, there may be progress in methods and standards, and these two kinds of progress depend on one another. Moreover, just as we need many (kinds of) mutually interacting and progressing theories and models to represent and explain the world, we need many (kinds of) interacting and progressing methods and standards for building and assessing those theories (including Deichsel's favourites, empirical adequacy, problem-solving capacity, and fit with the totality of current knowledge-themselves hard to apply unambiguously). Against this background, asking for a "unique" (perhaps final and fixed?) standard does not sound entirely appropriate. My view is strongly fallibilist regarding both theories about the world and the criteria for assessing those theories as to how well they provide us with epistemic access to the world.

I do think realism is important for avoiding "the worst kind of complacency" associated with mere rhetorical games, substitute modelling, derivational unification, intellectual autism. It is in terms of realism that these practices can be (descriptively) conceptualized in the first place, and can then be (normatively) identified as instances of misguided complacency that should be avoided. Preaching realism-also by showing that most economists already share realism regardless of what their self-understanding happens to suggest-is a way of trying to bring all parties at the same table. A genuine debate cannot even begin if some participants play a very different intellectual game (a game, the realist might add, that escapes issues of accountability in trying to solve the riddles of the universe and to help us manage our ways in it). If realism can contribute to the articulation of a shared framework within which progress-enhancing debate can take place, it comes to play a role in improving economics. If this is taken to justify realism, it is not compelling enough to preclude all further inquiry and debate. I doubt such a compelling justification will ever be forthcoming.

\section{REFERENCES}

Alston, William P. 1996. A realist conception of truth. Ithaca: Cornell University Press.

Deichsel, Simon. 2011. Against the pragmatic justification for realism in economic methodology. Erasmus Journal for Philosophy and Economics, 4 (1): 23-41. http://ejpe.org/pdf/4-1-art-2.pdf

Mäki, Uskali. 1996. Scientific realism and some peculiarities of economics. In Realism and anti-realism in the philosophy of science, eds. Robert S. Cohen, Risto Hilpinen, 
and Qiu Renzong. Boston Studies in the Philosophy of Science, vol. 169. Dordrecht: Kluwer Academic Publishers, 425-445.

Mäki, Uskali. 2005. Reglobalising realism by going local, or (how) should our formulations of scientific realism be informed about the sciences. Erkenntnis, 63: 231-251.

Mäki, Uskali. 2009. MISSing the world: models as isolations and credible surrogate systems. Erkenntnis, 70: 29-43.

Mäki, Uskali. 2011a. Models and the locus of their truth. Synthese, 180 (1): 47-63.

Mäki, Uskali. 2011b. Realism and antirealism about economics. In Handbook of the philosophy of economics, ed. Uskali Mäki. Amsterdam: Elsevier.

Mäki, Uskali. 2011c. Scientific realism as a challenge to economics (and vice versa). Journal of Economic Methodology, forthcoming.

Vision, Gerald. 2004. Veritas: the correspondence theory and its critics. Cambridge (MA): MIT Press.

Uskali Mäki is academy professor at the Academy of Finland, and director of the project Trends and Tensions of Intellectual Integration (TINT), based at the department of political and economic studies (philosophy), University of Helsinki. His research interests include philosophy of economics, economic methodology, philosophy of science, philosophy of social sciences, social studies of science, social ontology, social epistemology, and the rhetoric of inquiry.

Contact e-mail: <uskali.maki@helsinki.fi>

Website: <http://www.helsinki.fi/tint/maki> 